\title{
KARAKTERISTIK MANGROF DI DESA BANYU URIP KECAMATAN UJUNG PANGKA KABUPATEN GRESIK
}

\author{
Faisol Mas ud* \\ *Dosen Fakultas Perikanan Universitas Islam Lamongan \\ Jl. Veteran no. 53A Lamongan Phone/Fax.0322_324706
}

\begin{abstract}
ABSTRAK
Hutan mangrove merupakan salah satu ekosistem utama penyusun wilayah pesisir tropis selain pelagis estuaria, padang lamun dan terumbu karang. Desa Banyu Urip merupakan salah satu desa yang memiliki hutan mangrove yang belum adanya informasi mengenai karakteristik mangrove guna pemanfaatan yang berkelanjutan. Oleh karena itu tujuan penelitian ini untuk mengetahui karakteristik mangrove di Desa Banyu urip. Data yang dikumpulkan meliputi data mengenai jenis spesies, jumlah individu dan diameter pohon. Analisa data yang dilakukan menggunakan analisa kerapatan jenis, kerapatan relatif, frekuensi jenis, frekuensi relatif, penutupan jenis, penutupan relatif dan indek nilai penting. Berdasarkan hasil penelitian jenis mangrove yang ditemukan antara lain Avicennia marina, Rhizopora apiculata, Rhizopora mucronata, Excoecaria agallocha, Sonegratia alba, Bruguiera cylinrica. Mangrove yang memiliki indeks nilai penting tertinggi adalah Avicennia marina $(185,5 \%)$.
\end{abstract}

Kata Kunci : Mangrove, Ujung pangkah, Gresik, indeks nilai penting

\section{PENDAHULUAN}

Indonesia merupakan negara yang memiliki kekayaan sumberdaya hutan mangrove yang besar. Sekitar $61.250 \mathrm{~km}$ atau sepertiga mangrove dunia terdapat di Asia Tenggara, $42.550 \mathrm{~km}$ terdapat di Indonesia (Spalding et al., 1997 in Setyawan et al., 2002). Hutan mangrove merupakan salah satu ekosistem utama penyusun wilayah pesisir tropis selain pelagis estuaria, padang lamun dan terumbu karang. Hutan mangrove memiliki fungsi dan manfaat sebagai sumberdaya pembangunan, baik sebagai sumberdaya ekonomi maupun ekologi yang telah lama dimanfaatkan oleh masyarakat khususnya yang hidup di sekitar pesisir (Bonita \& Wahyu , 2014). Secara biologis hutan mangrove berfungsi sebagai tempat memijah dan berkembang biaknya berbagai hewan air, serta sebagai sumber plasma nutfah sedangkan jika secara ekonomi, hutan mangrove berfungsi sebagai penghasil kayu dan bahan bangunan, penghasil bahan baku industri, serta tempat pariwisata (Romadhon, 2008).

Buku Laporan SLHD Propinsi Jawa Timur (2010) menyatakan bahwa untuk wilayah Gresik sebagai besar mangrovenya telah direklamasi menjadi kawasan pergudangan dan industri. Penurunan luas kawasan mangrove yang terdapat di Indonesia akan mengakibatkan terjadinya biodervitas dan jasa lingkungan ekosistem mangrove menurun (Bengen, 2001). Begitu pentingya peran mangrove dalam ekosistem pesisir dan manusia, maka diperlukannya penelitian mengenai karakteristik mangrove di desa Banyuurip di Kecamatan Ujung Pangkah, Kab Gresik. 


\section{METODE PENELITIAN}

Penelitian ini dilaksanakan pada Maret - Mei 2017 di Desa Banyuurip Kecamatan Ujung Pangkah Kabupaten Gresik. Metode penelitian ini dilakukan secara deskriptif dengan pengambilan sampel metode transek garis dan petak contoh (Line Transect Plot) pada tiga stasiun (Gambar 1).

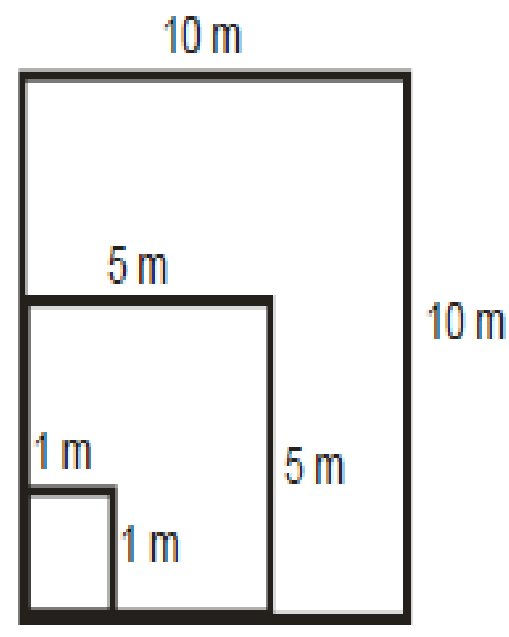

Keterangan :

$>10 \times 10 \mathrm{~m}$ untuk pengamatan fase pohon.

$>5 \times 5 \mathrm{~m}$ untuk pengamatan fase pancang (sapling).

$>1 \mathrm{x} 1 \mathrm{~m}$ untuk pengamatan fase semai (anakan).

\section{Analisa Data}

Data yang dikumpulkan meliputi data mengenai jenis spesies, jumlah individu dan diameter pohon. Data diolah dan dianalisis potensi ekosistem mangrovenya, analisa data yang dilakukan meliputi nilai kerapatan jenis, kerapatan relatif, frekuensi jenis, frekuensi relatif, penutupan jenis, penutupan relatif dan indek nilai penting.

Kerapatan Jenis $\left(\mathrm{D}_{\mathrm{i}}\right)$ adalah jumlah tegakan jenis $i$ dalam suatu unit area :

$$
D_{i}=\frac{n_{i}}{A}
$$

$\mathrm{D}_{\mathrm{i}}:$ Kerapatan jenis ke- $i$

$\mathrm{ni}_{\mathrm{i}}$ : Jumlah total tegakan ke- $i$

A : Luas area total pengambilan contoh

Kerapatan relatif (RDi) adalah perbandingan antara jumlah tegakan jenis $i$ dan jumlah total tegakan seluruh jenis $(\Sigma \mathrm{n})$ Menurut Curtis dan McIntosh (1950) yang digunakan adalah :

$$
R D_{i}=\frac{n_{i}}{\sum n} \times 100
$$

Keterangan:

RDi : Kerapatan relatif jenis ke-i.

ni : Jumlah total tegakan dari jenis ke- $i$.

$\Sigma \mathrm{n} \quad$ : Jumlah total tegakan seluruh jenis.

Frekuensi spesies (Fi) adalah peluang ditemukan suatu spesies ke-i dalam semua petak contoh dibanding dengan jumlah total petak contoh yang dibuat (Bengen 2000). Untuk menghitung frekuensi spesies (Fi) digunakan rumus :

$$
\mathrm{Fi}=\frac{P i}{\sum P i}
$$

Keterangan :

$\mathrm{Fi} \quad=$ Frekuensi spesies ke-i

$\mathrm{Pi}=$ Jumlah petak contoh tempat ditemukannya spesies ke-i

$\Sigma \mathrm{Pi}=$ Jumlah total plot yang diamati

Frekuensi relatif (RFi) adalah perbandingan antara frekuensi spesies ke-i dengan jumlah frekuensi seluruh spesies (Bengen, 2000). Untuk menghitung frekuensi relatif menggunakan rumus :

$$
\mathrm{RFi}=\frac{F i}{\sum F i} \times 100
$$

Keterangan :

Rfi = Frekuensi relatif spesies

$\mathrm{Fi} \quad=$ Frekuensi spesies ke-i

$\Sigma \mathrm{F}=$ Jumlah frekuensi untuk seluruh spesies 
Penutupan spesies (Ci) adalah luas penutupan spesies ke-i dalam suatu unit area tertentu (Bengen 2000).

$$
\mathrm{Ci}=\frac{B A}{\sum B A}
$$

Keterangan :

$$
\begin{aligned}
\mathrm{Ci}= & \text { Penutupan spesies } \\
\Sigma \mathrm{BA}= & \pi \mathrm{d}^{2} / 4(\mathrm{~d}=\text { diameter batang } \\
& \text { setinggi dada, } \pi=3,14) \\
\mathrm{A} \quad= & \text { Luas total area pengambilan } \\
& \text { contoh }\left(\mathrm{m}^{2}\right)
\end{aligned}
$$

Penutupan relatif (RCi) yaitu perbandingan antara penutupan spesies ke-i dengan luas total penutupan untuk seluruh spesies (Bengen 2000). Untuk menghitung $\mathrm{RCi}$, maka digunakan rumus :

$$
\mathrm{RCi}=\frac{C i}{\sum C i} \times 100
$$

Keterangan :

Rci = Penutupan relatif

$\mathrm{Ci}=$ Penutupan spesies ke- $\mathrm{i}$

$\Sigma \mathrm{Ci}=$ Jumlah total untuk seluruh spesies

Indeks nilai penting adalah jumlah nilai kerapatan jenis $\left(\mathrm{RD}_{\mathrm{i}}\right)$, frekuensi relative jenis $\left(\mathrm{RF}_{\mathrm{i}}\right)$, dan penutupan relative $\left(\mathrm{RC}_{\mathrm{i}}\right)$. Indeks Nilai Penting ini untuk memberikan suatu gambaran mengenai pengaruh atau peranan suatu jenis mangrove dalam ekosistem tersebut. ). Rumus awal INP oleh Curtis dan McIntosh (1950) adalah sebagai berikut:

$$
I N P=R D_{i}+R F_{i}+R C_{i}
$$

Keterangan :

$$
\begin{aligned}
& \text { INP }=\text { Indeks Nilai Penting } \\
& \mathrm{RDi}=\text { Kerapatan Jenis Relatif } \\
& \mathrm{RFi}=\text { Frekuensi Jenis Relatif } \\
& \mathrm{RCi}=\text { Penutupan Jenis Relatif }
\end{aligned}
$$

\section{HASIL \\ KARAKTERISTIK MANGROVE}

Komposisi jenis mangrove yang ditemukan di Desa Banyuurip Kecamatan Ujungpangkah Kabupaten Gresik secara umum di ketiga stasiun sebanyak 6 (enam) jenis yaitu; Avicennia Marina, Rhizopora apiculata, Rhizopora Mucronata, Excoecaria Agallocha, Sonegratia Alba, Bruguiera cylinrica. Hasil Identifikasi keberadaan jenis mangrove di lokasi penelitian menunjukkan, adanya perbedaan jenis dan kondisi mangrove di tiap stasiun pengamatan (Tabel 1)

Tabel 1. Analisa vegetasi Mangrove di Desa Banyu Urip

\begin{tabular}{cccccc}
\hline NO. & Jenis & $\begin{array}{c}\text { Kerapatan } \\
\text { relatif }\end{array}$ & $\begin{array}{c}\text { Frekuensi } \\
\text { Relatif }\end{array}$ & $\begin{array}{c}\text { Penutupan } \\
\text { Relatif }\end{array}$ & $\begin{array}{c}\text { Indek Nilai } \\
\text { Penting }\end{array}$ \\
\hline $\begin{array}{c}\text { Stasiun } \\
1\end{array}$ & Avicenia marina & 65 & 28.57 & 71.00 & 164.57 \\
& Rhizopora apiculata & 21.67 & 28.57 & 19.79 & 70.03 \\
& Rhizopora mucronata & 0 & 0 & 0 & 0.00 \\
& Excoecaria agallocha & 0 & 0 & 0 & 0.00 \\
& Someratia alba & 8.33 & 14.29 & 6.15 & 28.77 \\
& Bruguiera silindrica & 5 & 28.57 & 3.06 & 36.63 \\
\hline Stasiun & Avicenia marina & 73.84 & 42.31 & 71.48 & 187.62
\end{tabular}


Jurnal Grouper, September 2017 Vol 8 (2) : 15-20

ISSN $2086-8480$

\begin{tabular}{cccccc} 
& Rhizopora apiculata & 14.53 & 26.92 & 13.51 & 54.97 \\
& Rhizopora mucronata & 8.14 & 15.38 & 10.98 & 34.51 \\
& Excoecaria agallocha & 1.16 & 7.69 & 0.99 & 9.85 \\
Sonneratia alba & 2.33 & 7.69 & 3.04 & 13.06 \\
& Bruguiera silindrica & 0 & 0 & 0 & 0 \\
\hline Stasiun & Avicenia marina & 80.7 & 42.9 & 80.8 & 204.3 \\
& Rhizopora apiculata & 11.8 & 21.4 & 9.5 & 42.7 \\
& Rhizopora mucronata & 2.5 & 7.1 & 3.8 & 13.5 \\
& Excoecaria agallocha & 1.7 & 14.3 & 1.4 & 17.4 \\
Sonneratia alba & 3.4 & 14.3 & 4.4 & 22.1 \\
Bruguiera silindrica & 0 & 0 & 0 & 0 \\
\hline
\end{tabular}

Pada stasiun 1 merupakan area yang jenis mangrove paling sedikit hanya 4 (empat) spesies mangrove yaitu Avicenia marina, Rhizopora apiculata, Sonneretia alba, dan Bruguiera silindrica. Pada stasiun I tidak ditemukan pohon Rhizopora Mucronata, dan Excoecaria Agallocha sehingga hasilnya 0 . Pada stasiun II tidak ditemukan pohon Bruguiera cylinrica hasilnya 0. Sedangkan Pada stasiun III sama dengan stasiun II tidak ditemukan pohon jenis Bruguiera cylinrica. Untuk stasiun I tidak ada jenis Rhizopora

\section{Kerapatan Relatif}

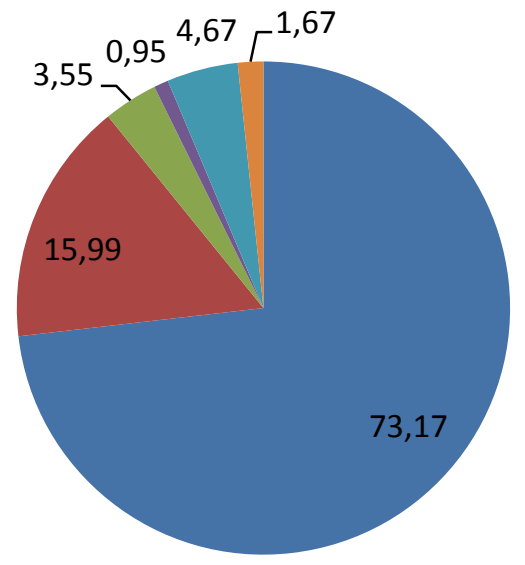

Mucronata dikarenakan Rhizopora Mucronata hidup di kondisi berpasir sedangkan stasiun I kondisinya berlumpur. Sedangkan stasiun II dan stasiun III tidak ditemukan pohon jenis Bruguiera cylinrica dikarenakan jenis ini tumbuh di kondisi berlumpur sedangkan stasiun II dan stasiun III kondisinya berpasir. Selain dari unsur hara dan matahari, faktor lain yang berpengaruh pada perbedaan kerapatan vegetasi adalah jenis substrat dan pasang surut air laut (Permadi et.al.,2016)

\section{Frekuensi Relatif}

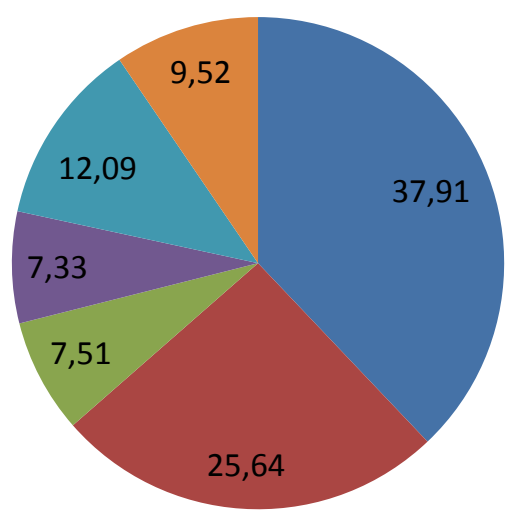




\section{Penutupan Relatif}

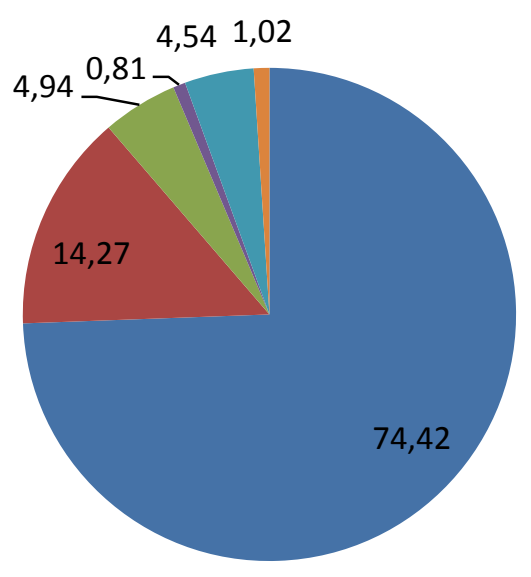

\section{Indek Nilai Penting}

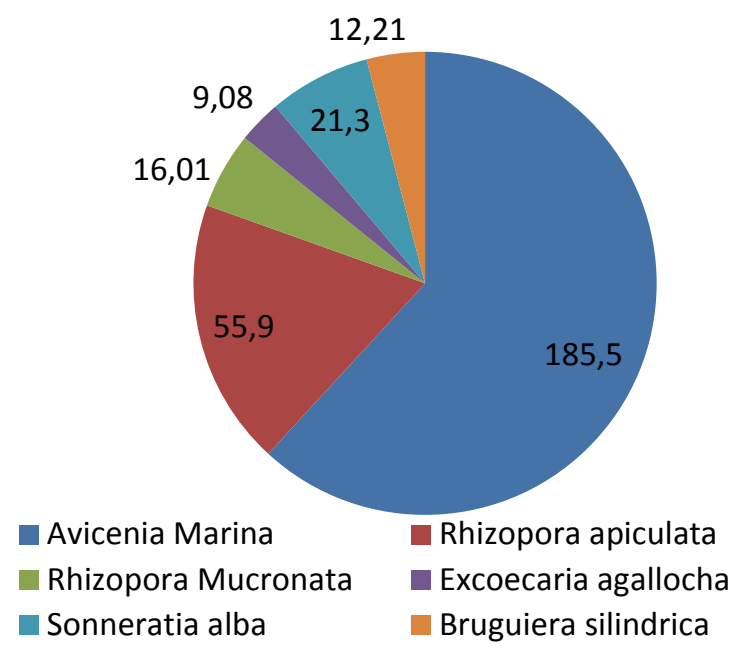

Gambar 2. Penutupan, Kerapatan, Frekuensi Relatif serta Indek Nilai Penting Mangrove di Desa Banyuurip Kec. Ujung Pangkah Kab. Gresik

Secara keseluruhan analisis vegetasi mangrove di Desa Banyuurip tercantum pada Gambar 2. Jenis Avicennia marina memiliki kerapatan yang lebih tinggi dibandingkan dengan jenis mangrove lain yang ditunjukkan pada nilai tinggi kerapatan relatifnya. Nilai frekuensi relatif menunjukkan penyebaran dan keberadaan tiap jenis mangrove yang dapat ditemukan pada setiap stasiun pengamatan. Avicennia marina dan Rhizopora apiculata merupakan mangrove yang penyebarannya merata dan keberadaannya sering ditemukan di seluruh area pengamatan. Nilai penutupan jenis relatif yang tinggi di Desa Banyu urip menunjukkan keberadaan mangrove jenis Avicennia marina mendominasi di seluruh area pengamatan.

Menurut Romadhon (2008) Nilai INP dari tiap jenis mangrove, sangat tergantung kondisi pertumbuhan mangrove. Mangrove untuk tumbuh dengan baik, memerlukan sejumlah faktor pendukung. INP menunjukkan kisaran Indeks yang menggambarkan struktur komunitas dan pola penyebaran mangrove (Supriharyono, 2007 dalam Parmadi et.al.,
2016) Tingginya nilai indeks penting (INP) mangrove pada Avicennia marina di Desa Banyuurip menunjukkan mangrove tersebut berperan cukup tinggi dalam menjaga keberlangsungan ekosistem. Perbedaan indeks nilai penting vegetasi mangrove dikarenakan adanya kompetisi pada setiap jenis untuk mendapatkan unsur hara dan sinar cahaya matahari pada lokasi penelitian (Parmadi et.al., 2016).

\section{KESIMPULAN}

Komposisi jenis mangrove yang ditemukan di Desa Banyuurip Kecamatan Ujungpangkah Kabupaten Gresik secara umum di ketiga stasiun sebanyak 6 (enam) jenis yaitu; Avicennia Marina, Rhizopora apiculata, Rhizopora Mucronata, Excoecaria Agallocha, Sonegratia Alba, Bruguiera cylinrica. Avicennia Marina adalah mangrove yang mendominasi dan berperan tinggi dalam ekosistem hutan mangrove di Desa Banyu Urip Kecamatan Ujung Pangkah Gresik. 


\section{DAFTAR PUSTAKA}

Bengen, D. G. 2001. Ekosistem dan sumberdaya pesisir dan laut serta pengelolaan secara terpadu dan berkelanjutan. Prosiding pelatihan pengelolaan wilayah pesisir terpadu. Bogor, 29 Oktober-3November 2001.

Bengen. D.G. 2000. Pedoman Teknis Pengenalan dan Pengelolaan Ekosistem Mangrove. Pusat Kajian Sumberdaya Pesisir dan Lautan. Institut Pertanian Bogor.

Bonita, M. K. dan Wahyu Y. N. 2014. Analisis Kerusakan Hutan Mangrove Di Wilayah Pesisir Sekotong Kabupaten Lombok Barat. Jurnal Media Bina Ilmiah.Vol 8 (1):64-71

Buku Laporan Status Lingkungan Hidup Daerah Provinsi Jawa Timur. 2010. Surabaya
Curtis, J.T dan McIntosh R.P. 1950. The Interrelations of Certain Analytic and Synthetic Phytosociological Characters. Ecology.Vol 31(3) : 434455

Permadi, E H., Irma D., Sofyatuddin K. 2016. Indeks Nilai Penting Vegetasi Mangrove di Kawasan Kuala IDI, Kabupaten Aceh Timur. Jurnal Ilmiah Mahasiswa Kelautan dan Perikanan Unsyiah.Vol 1(1) : 82-95

Romadhon, A. 2008. Kajian Nilai Ekologi Melalui Inventarisasi dan Nilai Indeks Penting (INP) Mangrove Terhadap Perlindugan Lingkungan Kepulauan Kangean. Jurnal EMBRYO. Vol 5 (1): 82-97

Setyawan, A. D., Kusumo W, dan Purin C. P. 2002. Ekosistem Mangrove di Jawa : 1. Kondisi Terkini. BIODIVERSITAS. Vol 4(2): 133145 